\title{
Voice- and Touch-Controlled Checklists
}

\author{
https://doi.org/10.3991/ijac.v13i2.17037 \\ Fernando Salvetti $(\bowtie)$ \\ Centro Studi Logos, Turin, Italy - Logosnet, Lugano, Switzerland and Houston, TX, USA \\ salvetti@logosnet.org \\ Roxane Gardner \\ Center for Medical Simulation, Boston, MA, USA \\ Brigham and Women's Hospital / Children's Hospital / Massachusetts General Hospital/ \\ Harvard Medical School, Boston, MA, USA \\ Rebecca Minehart \\ Center for Medical Simulation, Boston, MA, USA \\ Massachusetts General Hospital / Harvard Medical School, Boston, MA, USA \\ Barbara Bertagni \\ Centro Studi Logos, Turin, Italy - Logosnet, Lugano, Switzerland and Houston, TX, USA
}

\begin{abstract}
From day 1 of training, pilots learn to utilize mnemonics, acronyms and aphorisms to remember checks, procedures and practices - and these techniques remain with them throughout their careers. Learning to use such memory aids effectively can help pilots in at least two distinct ways; it frees up working memory during routine operations and directs the mind towards required actions during situations and emergencies. Surgeons, physicians, paramedic personnel, and nurses are often invited to do the same. The amount of information and the level of detail included in checklists are among the most difficult issues to control during the development process of these tools, since there is no universal model of representation regarding iconography, text length, density of information, number of steps, colors, fonts, etc., regarding any of the elements involved in the system. Communication patterns, knowledge visualization strategies and techniques, and the ways to interact with the checklist are other challenging issues.
\end{abstract}

Index Terms - Checklist, Knowledge Visualization, e-REAL Simulation

\section{$1 \quad$ Mnemonics and Checklists}

In aviation, pilots often say that the checklist is probably the most important document in any aircraft. If they forget to use it on a routine flight, they could land with the gear up, or worse. Distractions or the slip of a finger can result in a missed checklist item. One way to double-check the checklist is with a mnemonic phrase or memory 
jogger. Pilots have been coming up with these clever reminders since the dawn of aviation.

While most pilots are conscientious about using checklists for the runup, the CIGAR mnemonic is a good backup. CIGAR stands for Controls check, Instruments set, Gas (fuel on proper tank, pump on), Attitude (flaps and trim set) and Runup (magnetos check). Most runup checklists are more extensive, but the CIGAR check accomplishes the common items that are critical in the majority of small aircraft. It is particularly useful when a complete runup isn't required, such as after landing when you plan to immediately taxi back for another takeoff [1].

"Lights, Camera, Action" is another good example of a convenient pre-takeoff crosscheck. Lights include strobe, landing light, and navigation lights (on as necessary). Camera refers to the transponder, which helps air traffic control "see" and identify you on radar. The meaning of action varies from one pilot and aircraft to another, but it's often used to remember items such as the fuel boost pump, controls check, flaps, and trim.

A mnemonic is any technique that assists the human memory with information retention or retrieval by making abstract or impersonal information more accessible and meaningful, and therefore easier to remember. Many of them are acronyms or initialisms which reduce a lengthy set of terms to a single, easy-to-remember word or phrase.

From day 1 of training, pilots learn to utilize mnemonics, acronyms and aphorisms to remember checks, procedures and practices - and these techniques remain with them throughout their careers. Learning to use such memory aids effectively can help pilots in at least two distinct ways; it frees up working memory during routine operations and directs the mind towards required actions during situations and emergencies.

Surgeons, physicians, paramedic personnel and nurses are often invited to do the same. To handle the complexity of the medical world, mnemonics and cognitive tools may work very well. Examples from healthcare are: PIPPA, used for airway assessment, that stands for Position, Inspection, Palpation, Percussion, Auscultation; ASTHMA, aptly named for asthma management, that stands for Adrenergic agonists, Steroids, Theophylline, Hydration, Masked oxygen, Anticholinergics [2].

Medicine is cognitively complicated, due to its breadth and quantity of knowledge. So, it is the execution - the practical aspect of what that knowledge requires medical personnel to do - that is the most essential. The damage that the human body can survive these days is as awesome as it is horrible: this requires a panoply of technology - for example a mechanical ventilator and perhaps a tracheostomy tube if the lungs have failed, or an aortic balloon pump if the heart has given out. Here is the fundamental puzzle of modern medical care: you have a desperately sick patient and in order to have a chance of saving him, or her, you have to get the knowledge right and then you have to make sure that the 178 daily tasks that follow are done correctly. Yet it is far from obvious that something as simple as a checklist could be of substantial help. We may admit that errors and oversights occur. Mapping out the proper steps for every case is not possible, and healthcare providers have been skeptical that a piece of paper with a bunch of little boxes would improve matters [3] [4]. 
Faulty memory and distraction are a particular danger in what engineers call all-ornone processes: if a single key operation is missed, the entire effort might be made futile. Checklists seem to provide protection against such failures. They remind us of the minimum necessary steps and make them explicit.

\section{Checklist Design and Usability}

The amount of information and the level of detail to be included in checklists are among the most difficult issues to control during the development process of these tools, since there is no universal model of representation regarding iconography, text length, density of information, number of steps, colors, fonts, etc., regarding any of the elements involved in the system. Communication patterns, knowledge visualization strategies and techniques, and the ways to interact with the checklist, are other challenging issues.

At the Center for Medical Simulation (CMS) in Boston, Massachusetts, as well as at the Centro Studi Logos in Turin, Italy, (which is the applied research center of excellence from Logosnet), tests are performed, based on different visualizations of the same content. Tests are also carried out on the use of different communication channels to interact with the content, for example voice recognition or touch inputs for visual navigation, instead of only simple reading.

We started from the Emergency Manual prepared by the Stanford Anesthesia Cognitive Aid Group [5], characterized by content that is optimized to facilitate clinical use in conditions of high stress. The tests and research being performed at CMS since 2018 are aimed at understanding if there is a maximum amount of information to be included in checklists and what the optimal level of detail is; different communication channels are explored as well.

Simulation enables the study of various aspects of clinical practice that may not otherwise be measurable, and conditions may be controlled significantly more in the simulated setting [6][7].

The design of simulated clinical scenarios is complex and encompasses a wide range of components to replicate the clinical setting. Currently at CMS, scenario design for applied research on checklists is ongoing, as well as checklist redesign in order to test solutions with iconography, graphics and content density.

Currently, some different checklist templates have been released and usability tests are ongoing. Template 0 is the one from the Emergency Manual by Stanford Anesthesia Cognitive Aid Group (Figures 1 and 2). Different visualizations of the same content are available below as well (Figures 3 to 6 ). 

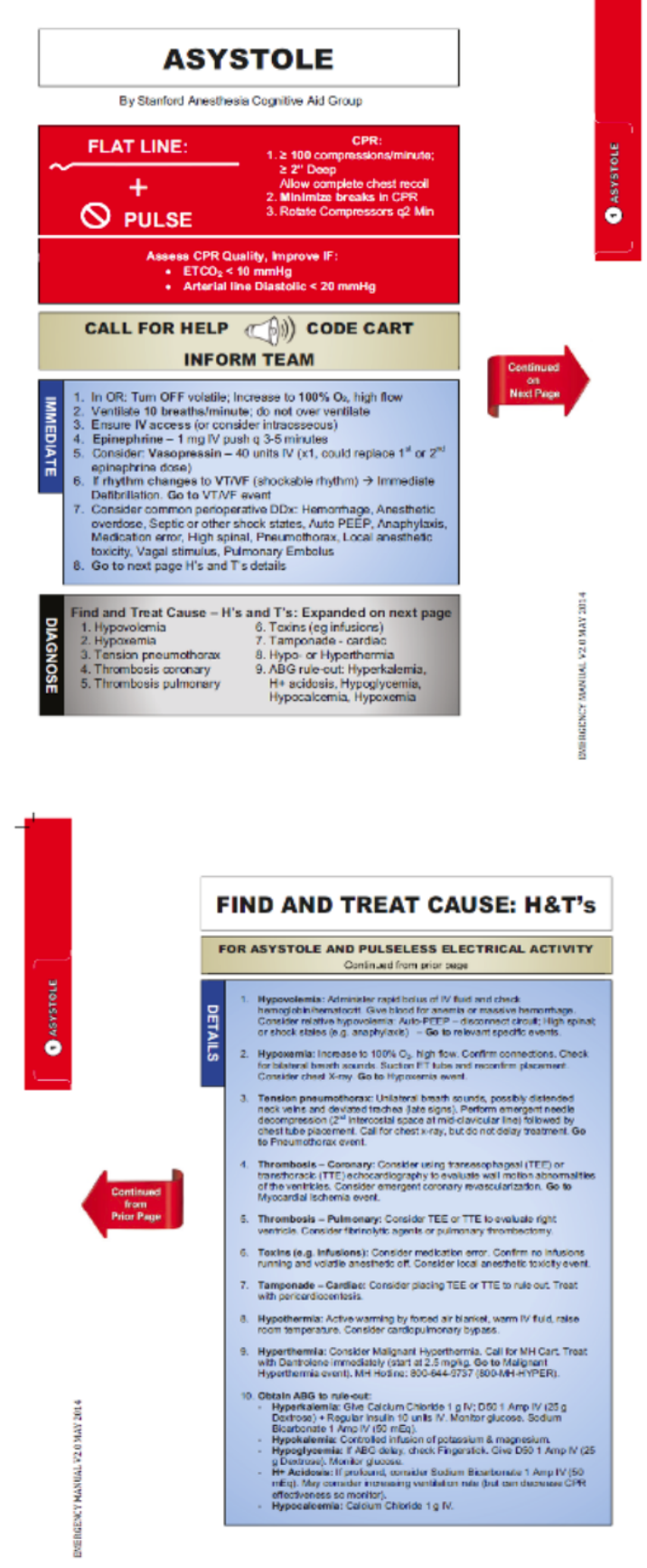

Fig. 1 and 2. Standard template from the Emergency Manual by Stanford Anesthesia Cognitive Aid Group 


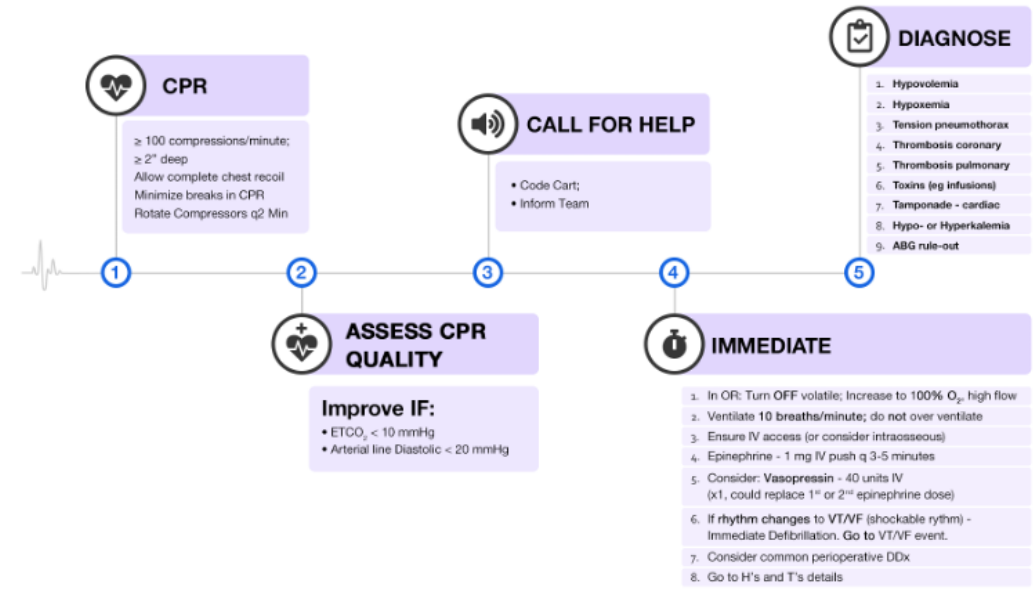

ASYSTOLE FLATLINE + NOPULSE

\begin{tabular}{|c|c|c|}
\hline $\begin{array}{l}\text { 1. } \geq 100 \text { comp } \\
\geq 2 " \text { deep } \\
\text { 2. Allow compl } \\
\text { 3. Minimize bre } \\
\text { Rotate Com }\end{array}$ & $\begin{array}{ll}\text { ssions/minute; } & \begin{array}{l}\text { Assess CPR Quality, } \\
\text { Improve IF: } \\
\text { te chest recoil (2) } \\
\text { iks in CPR } \\
\text { essors q2 Min }\end{array} \\
\begin{array}{ll}\text { ETCO } \\
\text { esterial line Diastolic }<20 \mathrm{mmHg}\end{array}\end{array}$ & $\begin{array}{l}\text { CALL FOR HELP } \\
\text { Code Cart; } \\
\text { Inform Team }\end{array}$ \\
\hline IMMEDIATE & $\begin{array}{l}\text { 1. In OR: Turn OFF volatile; Increase to } 100 \% \mathrm{O}_{2} \text {, high flow } \\
\text { 2. Ventilate } 10 \text { breaths/minute; do not over ventilate } \\
\text { 3. Ensure IV access (or consider intraosseous) } \\
\text { 4. Epinephrine - } 1 \text { mg IV push q } 3-5 \text { minutes } \\
\text { 5. Consider: Vasopressin - } 40 \text { units IV } \\
\text { ( } x 1 \text {, could replace } 1^{\text {trt }} \text { or } 2^{\text {nd }} \text { epinephrine dose) } \\
\text { 6. If rhythm changes to VT/NF (shockable rythm) - } \\
\text { Immediate Defibrillation. Go to VT/NF event. } \\
\text { 7. Consider common perioperative DDx } \\
\text { 8. Go to H's and T's details }\end{array}$ & $\begin{array}{l}\text { Consider common } \\
\text { perioperative DDx: } \\
\text { - Hemorrhage, } \\
\text { - Anesthetic overdose, } \\
\text { - Septic or other shock } \\
\text { states, } \\
\text { - Auto PEEP, } \\
\text { - Anaphylaxis, } \\
\text { - Medication error, } \\
\text { - High spinal, } \\
\text { - Pneumothorax, } \\
\text { - Local anesthetic toxicity, } \\
\text { - Vagal stimulus, } \\
\text { - Pulmonary Embolus }\end{array}$ \\
\hline
\end{tabular}

Fig. 3 and 4. Alternative visualization, first release 


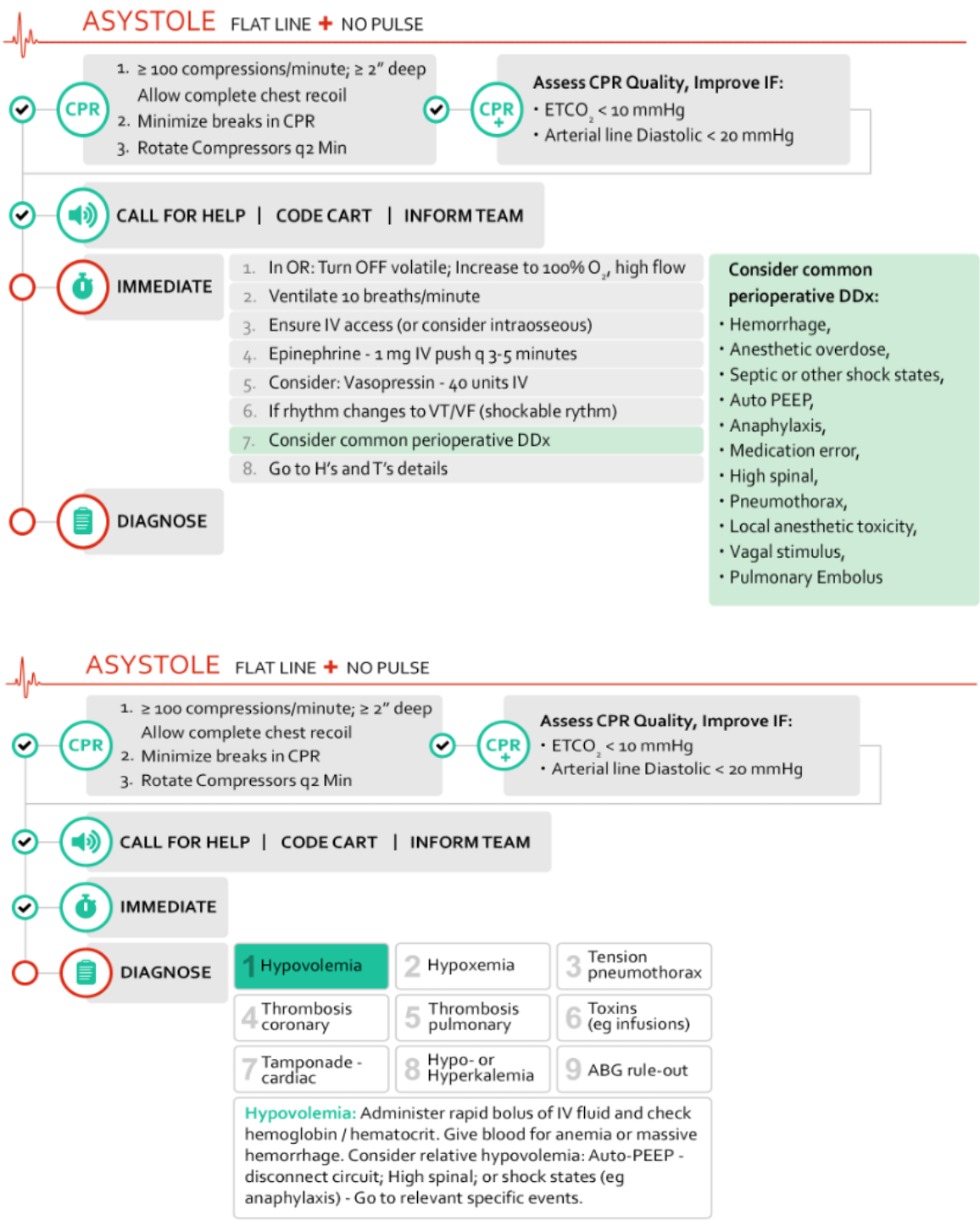

Fig. 5 and 6. Alternative visualization, second release

Usability refers to the use of either a paper version of these checklists or to their electronic versions displayed on a monitor/wall and controlled by voice and/or touch commands. This tests the use of different communication channels to interact with the content-voice recognition or touch inputs for visual navigation versus just simple reading on a paper.

Visualization on monitors or walls is made by the e-REAL ${ }^{\circledR}$ technology [8]. The simulation setting is displayed below (Figures 7-11). 

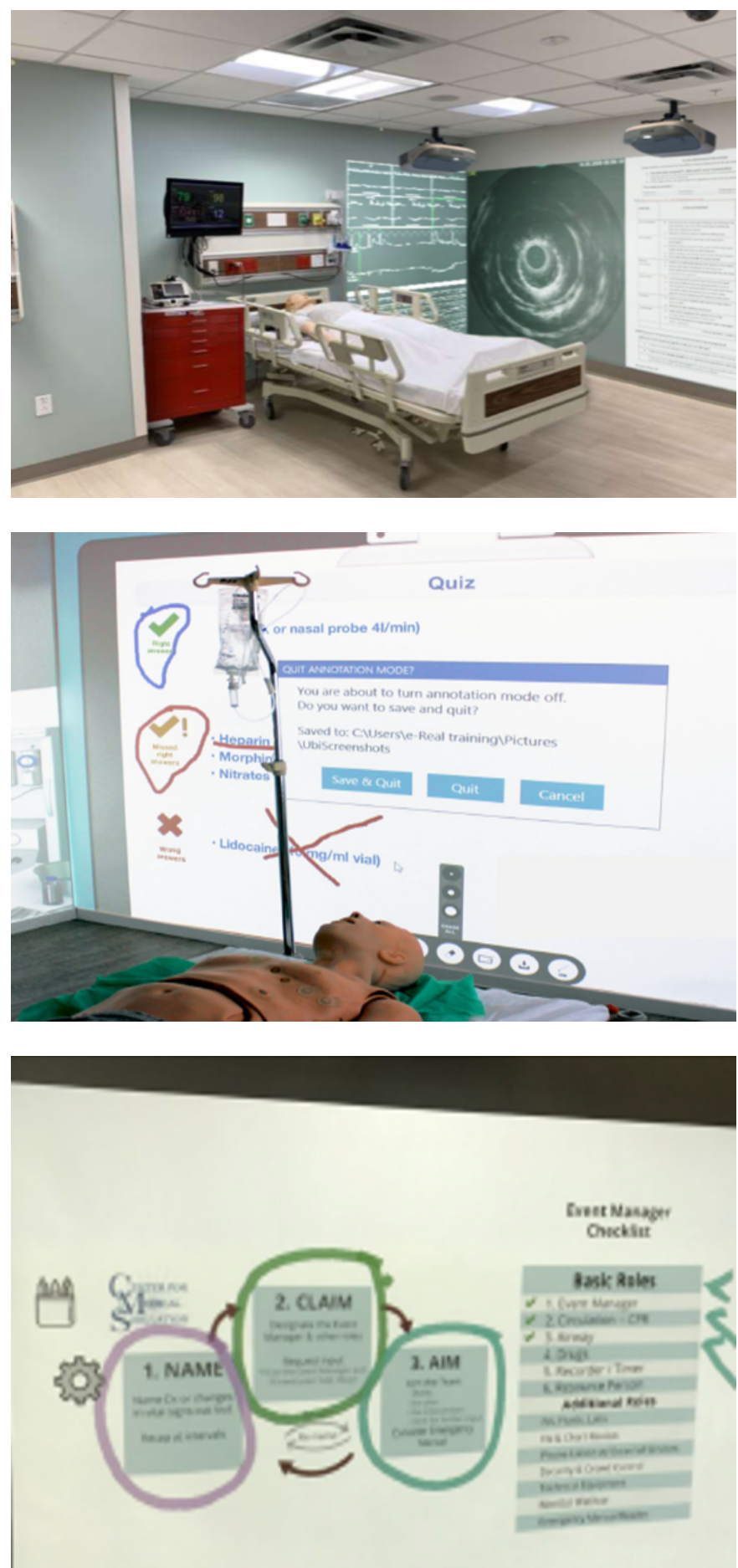

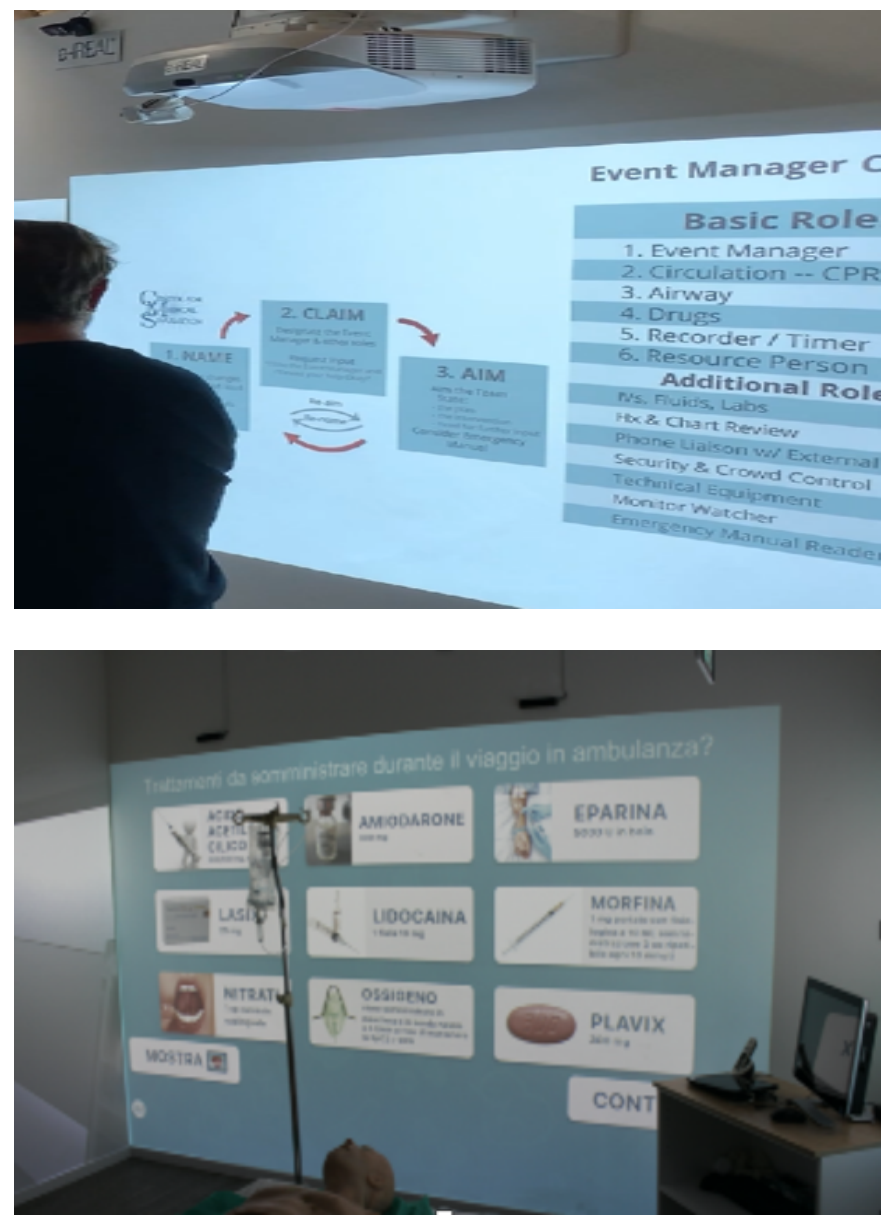

Fig. 7-11. Checklists visualization by the e-REAL $®$ technology

The main research hypothesis is that visualization and voice recognition can improve any complex operational process better than simple checklist reading by a member of the healthcare team.

A short questionnaire is being used as a control tool at the end of each simulation module in order to collect performance data and measure learning outputs, allowing a better understanding of which checklist works better.

Initial research findings from the simulation activity seem to be consistent with the main research hypothesis. 


\section{$3 \quad$ References}

[1] Helmreich, R.L., Merritt, A.C. and Wilhelm, J.A., 1999. The evolution of crew resource management training in commercial aviation. The International Journal of Aviation Psychology, 9(1), pp.19-32. https://doi.org/10.4324/9781315092898-15

[2] Bellezza, FS. (1996). Mnemonic Methods to Enhance Storage and Retrieval. Memory, 345380. https://doi.org/10.1016/b978-012102570-0/50012-4

[3] Gawande, A. (2009). The Checklist Manifesto. New York: Metropolitan Books.

[4] Low, D. \& C. (2011). A randomised control trial to determine if use of the iResus application on a smart phone. Anaesthesia n. 66, p. 255-262. https://doi.org/10.1111/j.13652044.2011.06649.x

[5] Gaba D. \& C. (2011). Emergency Manual Cognitive Aids for Perioperative Critical Events.

[6] Salvetti, F., Gardner, R., Minehart, R., Bertagni, B. (2019). Teamwork and Crisis Resource Management for Labor and Delivery Clinicians: Interactive Visualization to Enhance Teamwork, Situational Awareness, Contextual Intelligence and Cognitive Retention in Medical Simulation. ICELW 2019, Columbia University, New York.

[7] Munroe, B., Buckley, T., Curtis, K., Morris, R. (2016), Designing and Implementing Full Immersion Simulation as a Research Tool. Australasian Emergency Nursing Journal, 19, 90-105. https://doi.org/10.1016/j.aenj.2016.01.001

[8] www.e-real.net/healthcare.

\section{$4 \quad$ Authors}

Fernando Salvetti (J.D., P.P.E., M.Phil., Ph.D.), Founder of Centro Studi Logos in Turin and Logosnet in Lugano, Berlin and Houston, is an epistemologist, an anthropologist and a lawyer who co-designed e-REAL, the enhanced reality lab where virtual and real worlds are merging within an advanced simulation environment. He is committed to exploring virtual and augmented reality, cognitive aids by artificial intelligence, visual thinking, interactive and immersive learning, emerging scenarios and trends, and cross-cultural intelligence (salvetti@logosnet.org).

Roxane Gardner (M.D., M.H.P.E., M.P.H., Ph.D.), Senior Director for Clinical Programs and Director of the Visiting Scholars and Fellowship Program at the Center for Medical Simulation in Boston (CMS), has been a principle faculty member of CMS since 2002 and Co-Director of its Labor and Delivery Teamwork and Crisis Management program since its inception in 2003. In addition to her roles at CMS, Dr. Gardner is an Assistant Professor of Obstetrics, Gynecology and Reproductive Biology at the Harvard Medical School and holds appointments in Boston at Brigham and Women's Hospital, Boston Children's Hospital, and Massachusetts General Hospital (rgardner1@bwh.harvard.edu).

Rebecca D. Minehart (M.D., M.S.H.P.Ed.), Director for Anesthesia Clinical Courses at the Center for Medical Simulation in Boston (CMS), is an obstetric anesthesiologist at Massachusetts General Hospital (MGH), an Assistant Professor of Anesthesia at Harvard Medical School, and the Program Director for the MGH Obstetric Anesthesia Fellowship Program. She is an ardent education and patient safety advocate who has been involved in international efforts to both research and promote best teamwork and communication practices, especially involving speaking up and 
giving feedback. She is a recognized expert in educational techniques utilizing simulation and is a core teaching faculty member at both CMS and the MGH Learning Laboratory, where she serves as the Operating Room Simulation Officer (rminehart@mgh.harvard.edu).

Barbara Bertagni (B.Sc., B.A., M.A., M.Phil., Ph.D., Clin.Psy.D), Founder of Centro Studi Logos in Turin and Logosnet in Lugano, Berlin and Houston, as well as e-REAL co-designer, is a clinical psychologist, an anthropologist and a practical philosopher particularly involved with personal and professional development, coaching and mentoring, immersive learning and advanced simulation. She is interested in design and foster learning solutions, involving both cognition and emotion, to help people developing competencies that enhance individual and organizational performance. She works as a sparring partner, advising people and organizations across the globe (bertagni@logosnet.org).

Article submitted 2020-07-11. Resubmitted 2020-08-03. Final acceptance 2020-08-05. Final version published as submitted by the authors. 